\title{
New Economic Anthropology Paradigm with Chinese Characteristics: On Yang Tingshuo's Interphase Operational Development Theory
}

\author{
Guang Tian \\ Huaihua University \\ Youchun Jiang (Corresponding Author) \\ Huaihua University
}

The interphase (xiangji) operational development model proposed by the Chinese scholar Yang Tingshuo has made a unique contribution to localize economic anthropology in China. The way to localize economic anthropology in China is through applying the theories and methods of economic anthropology to minority areas during China's economic development; investigating and solving the problems of the minorities through effective policy making; and then by formatting the new theory models. This paper probes and summarizes the path model of localizing economic anthropology with Chinese characteristics by examining Yang's interphase operating principle model from different perspectives.

Keywords: Interphase Operational Principle, Theoretically Rethinking, Chinese Characteristics, Policy Proposals

\section{INTRODUCTION}

In China, anthropology is in its development stage while economic anthropology, as a branch of applied anthropology, is still in its initial stage. It was actually introduced in China about 70 years ago (Zhou 2013). Early economic anthropology focused on the study of rural economies (Shi 2002). After the People's Republic of China was established, the central government organized an intensive project to study economic and social development issues in ethnic minority areas in order to promote the comprehensive development of the social economy of those areas. This project laid a solid foundation for growth of economic anthropology in China.

The process of localizing the economic anthropology in China started in 1970s. It was after 10 years, when developing Western China campaign was officially launched by the central government in the early 1980s (Tian, et al. 1987). At the same time, some scholars started a sub-field of economics termed as minzu (ethnic) economics (Shi 1993). These two activities were the symbol of economic anthropology localization with Chinese characteristics in China. In the course of economic anthropology localization in China, scholars proposed several well-accepted paradigms. These paradigms included a framework which suggested that the interests of ethnic economies were relatively independent (Li 2003); a model which exhibited the rational reflection of the modernization process (Chen 2000), and the interphase operational model theory (Yang1995). These new paradigms not only enhanced the localization of economic 
anthropology in China but also contributed to the theoretical development of economic anthropology in general.

The path to localization of economic anthropology in China includes applying economic anthropology theories and methods to study social economic development issues in the country in general, and to discover and solve various problems for the social economic development particularly in minority areas. This is not simply to introduce western theories and models as a diffusion paradigm. A paradigm dealing with economic and social development in minority areas is a pragmatic paradigm. It is true that a pragmatic paradigm alone is not sufficient for this. Therefore, it is necessary to contribute to the theoretical construction of economic anthropology as well as to conceptualize the models of social economic development in China focusing on western China where ethnic minority people are concentrated. The research approach of utilizing a good understanding of western economic anthropological theories and methods, and employing intensive economic anthropology fieldwork may be termed as a theorization paradigm (Fan 2009).

Both the pragmatic and theorization paradigms are necessary for localization of economic anthropology in China. These two paradigms are not irreconcilable or opposed to each other. Instead, they are interdependent for the development of economic anthropology in China. The ideal paradigm has following three steps: 1. Borrow theories and methods from western economic anthropology, 2. Take China's national conditions as the starting point, 3 . And thoroughly study the social economic issues faced by China in its efforts for development, especially social and economic development problems in concentrated ethnic minorities regions. These studies not only need to follow the paradigms of classical economic anthropology, but they also require taking Chinese traditions and the current situation of ethnic minority regions into consideration. Based on the fieldwork data and information from intensive investigations, economic anthropologists will be able to put forward suggestions to decision makers for designing operable policies and then implementing a plan for carrying out the policies. Further, by rethinking the western economic paradigm, they should be able to propose new theoretical paradigms according to the fieldwork findings and to suggest new policies along with the implementation plan to build up economic anthropology with Chinese characteristics. This combined comprehensive approach is a significant path for development of economic anthropology in China.

The famous Chinese economic anthropologist Yang Tingshuo has conducted economic anthropology studies for several decades and has made unique contributions to the development of economic anthropology in China (Tian 2014). His most appraised and cited monograph Principles in Xiangji Operation serves as the model of a combined comprehensive approach for localization of economic anthropology. The xiangji (interphase) economic principle theoretical model drew scholars' intense attention at the very beginning when it was proposed (Feng 1995). It was listed as one of the greatest contributions by Chinese scholars to the development of economic anthropology theory. Yang's work deserves a just appreciation as far as economic anthropology as well as the localization of economic anthropology in China is concerned. In addition, it may be significantly helpful for us to constantly probe and explore the intrinsic value of the theoretical model proposed by Yang, particularly its social practice guidance value to China's national comprehensive well-being (Tian and Luo 2013:373-389). This paper explores Professor Yang's interphase economic principle theoretical model from different angles, and discusses its value and significance in the both aspects of theory and practice.

\section{XIANGJI (INTERPHASE) OPERATING PRINCIPLES}

Professor Yang Tingshuo has long been engaged in teaching and research work in the fields of economic anthropology and ethnic economics. His main research interests include ecological anthropology, history of national development, and ecological history of China. Well known among Chinese domestic economic anthropologists and ethnographers, Yang has published several books on economic anthropology, and played an important role in promoting economic anthropology and development ethnology, especially the development of ecological anthropology in China. Yang's contribution to economic anthropology is embodied in Principles in Xiangji Operation: Theories and 
Practices on Economic Activities across Ethnic Groups (hereinafter referred to as Yang's book); it was published by Guizhou Nationalities Publishing House in 1995.

We should not underestimate the contributions and the significance of Yang's masterpiece book to the localization of economic anthropology in the Chinese context, nor should we underestimate its theoretical contribution and practical role in guiding the economic development of Western China Minority Regions (WCMR). Professor Yang, through a comprehensive investigation and literature review, proposed a positive solution to major social and economic issues that China currently faces. He illustrated how non-economic factors affect the social and economic development in WCMR regions, demonstrated the history and their effective causes. Moreover, he discussed how to assess the specific role of non-economic factors in economic development in the region; how to identify the relationship between promoting the development of production and non-economic factors; and how to avoid and overcome non-economic factors' adverse impact on economic development. Yang pointed out that the history and reality force people become aware of non-economic factors, to accordingly make a systematic study of the development in the developing countries, and to find the overall economic and social development solutions for the economically backward regions. He made his point through analyzing and summarizing the theoretical models about social economic development in backward areas both domestically and internationally (Yang 1995:2).

Yang's book not only put forward the new political economics' concept of "developing ethnic group", but also generated concise and original thinking about the xiangji (interphase) economic principles theoretical model. This is the major contribution that Yang's book made to economic anthropology with strong Chinese characteristics. According to Yang's book and our own understanding, xiang refers to phase, pronounced xiang (fourth sound in Mandarin Chinese pronunciation) and has rich meanings. Firstly, it refers to a person's appearance, such as photography, the table manner. Secondly, it refers to the appearance of objects, such as the moon, sea surface. Thirdly, it refers to actions of seeing or judging, such as observing, physiognomy. Fourthly, it is an official title, such as the prime minister. Fifthly, it refers to some physical or chemical material state, such as steam, water, ice, which is water in three different phases. Sixthly, it refers to sinusoidal physical quantities, in a time (or a position) state, and can be a measurement to determine the value of time or position, called "phase". Therefore, xiang (phase) is full of complex content with multiple meanings. In Yang's book, xiang (phase) refers to different economic, social and cultural environments as well as the different national economic operational modes and their scopes and characteristics. It also refers to those economic operational models which are all within certain limitations of scope and administration, including natural, historical, political, cultural and other factors.

Yang points out that human economic activity is carried out in culture under certain laws and in a particular environment. The function of the state and its administration of culture and environment have a direct influence on human economic activities (Yang 1995:17). The concept of xiang (phase) refers to different natural, economic, social and cultural environments; relationship, influence, scope and characteristics of the different factors; as well as the relations and interactions between the different national economic operational modes. The concept of xiang (phase) is derived from historical processes and each nation has its own historical process. In addition, each nation has its own contacts with neighboring ethnic groups and with the history of political and legal system of other nations. The concept stresses more on living environment surrounding the processing, transformation and use of materials. It highlights the society and its natural characteristics by coupling concise national cultures under the law as a xiang (phase). Yang's theoretical model highly abstracts from both the Chinese classical philosophical tradition and the modern Chinese reality and is consistent with the modern natural science idea. Therefore, speculative philosophy and interdisciplinary integration include the new concept of xiang (phase) and is far more comprehensive and meaningful than what can be expressed by the traditional "ethnic" concept.

The Xiangji (interphase) economic principle theoretical model is based on the skilled grasp, digestion, absorption and comprehensive understanding of cultural anthropology, economic anthropology, and economic theory developed both inside China and in the outside world. This theoretical model has 
exceeded the traditional economics assumption of "the rational individual", as well as its abstractive way of thinking on human economic activities. It goes beyond traditional anthropological theory of motivation and cultural impact on decision making by adopting a comparative paradigm of human economic activity. It has brought the development of economic anthropology to a new climax, and at the same time, it has advanced the localization development of economic anthropology in China and enriched the economic anthropology theory with Chinese characteristics (Tian 2013).

\section{REFLECTION ON WESTERN ECONOMIC ANTHROPOLOGY THEORY}

As a product of dialogue between anthropology and economics, economic anthropology takes human economic behavior as the research object, but differs from a purely economic understanding (Carrier 2005). It has gone through different stages of development and is coming into a new stage in order to study the world economy as a whole (Dalton 1971). Traditionally, economic anthropologists study human economic behavior by taking Western intellectual history as the background, which generates some limitations. Therefore, we must have a newer and wider perspective to investigate economic activities, needs and motivation of human beings (Han and Hart 2011; Schrauwers 2011).

In its earlier development stage, western economic anthropology research conventionally focused on non-traditional western nations as the subject of study in order to treat the research objects as "contemporary primitive peoples" or "contemporary backward nations". In the view of western economic anthropologists, the development of these minorities was in an early stage of development when compared to the development of a western nation; and the purpose of their research was to illustrate the development of human society. In light of their theoretical assumptions, these so-called backward nations would eventually give up their traditional culture values and embrace western thoughts through the appeal of western civilization. Yang seriously criticizes this point of view and indicates that western economic anthropologists, in their academic thought and research, have failed to take the realistic differences into account. Moreover, the differences have existed for a long period between the western and non-western nations; let alone have western anthropologists contemplated establishing ethnic equality as well as a mutually beneficial relationship of reciprocity between the western and non-western nations. Because of this, their theoretical and practical research accomplishments have limited practical value in the context of Chinese society (Yang 1995:28).

Yang points out that the early western anthropologists, in their analysis of economic activities among different nations, often put their own nation at the peak of development, believing that their economic way of life was the natural end of economic development and that their way of life could be applied to every nation in the world. Accordingly, they think that more the non-western nations accept western values and economic system, higher will be their standard of living. According to Yang, westerners believe that if non-western countries refuse to accept western ways, these countries will be backward forever. Apparently, in their way of thinking, western economic anthropologists believe that modernization for non-western nations is equal to westernization. As such, they only apply existing western values to deal with the problem of economic activities between different nations. This viewpoint sounds overtly in favor of racists, and therefore has gone beyond the boundaries of academic affairs. Yang suggests that we must rethink this single-minded evolutionary pattern, and that we should not believe that it reflects the essence of existence. He denies that this model, which exhibits a pattern of single-minded development, is reliable. He rather asserts that we must conduct research based on development in multiphase and multiple paths in order to carry out the development of economic anthropology (Yang 1995:29).

Two major schools existed in the history of economic anthropology, namely substantialism and formalism. The great debate between the two schools is a historical process for the development of economic anthropology (Ortiz 1983). Significant differences existed between these two schools, including proper objects of study, research purpose, and research methods. For example, the research objective for the substantialism school is to emphasize that economic activities of non-western peoples differ from that of western peoples, and therefore should be treated differently. On the other hand, the formalism school 
argues that the economic activities of non-western peoples have internal similarities with current western economic law and therefore should be treated in the same way. The purpose of the formalism school is to provide a theoretical basis for the western developed countries to investigate their global economic activities. From the methodological perspective, most substantialists perform their research at a microeconomic level, while most advocates of formalism are good at macroeconomic studies (Mayhew 1980).

After a detailed inventory of the arguments from both schools, Yang analyzes differences between the two sides and indicates that human economic activities have common characteristics by their very nature from a macro point of view. However, each individual nation's economic activities are the product of a specific culture under law. Because traditional culture differs among various peoples, the corresponding economic life will be richly different in both format and substance. Because of this, from the microeconomic point of view, there is an essential difference in terms of economic activities of various peoples. The key issue here is to combine both macro and micro levels together to recognize the coexistence of essential consistency and the specific differences so that we can better grasp the substantive characteristics of economic development of human society (Yang 1995:37).

Culture is one of the most important research contents for economic anthropologists. Anthropologists believe that all human activities are constrained by their cultural value system with no exception for economic activities (Gudeman 2001). Economic anthropologists apply the cultural concept in all aspects of their research without any exception (Hann, Hart 2011). Economic anthropology principles state that culture will generate specific preferential viewpoint or context cognition to explore the truth as reference for groups and individuals. Culture is essential as a factor in the economy, just like labor, land, and capital (Halperin 1988). However, traditional western economic anthropology theory lacks in fully understanding the culture and thus is not integrated (Hornborg 2005). In other words, traditional western economic anthropology theory has failed to look at various elements of culture as a part of the whole; the existence of the interdependence between those elements; and the symbiotic relationship of the coexisting elements (Nash 1981). Based on this understanding, Yang puts forward the argument that we must consider them from the perspective of culture as whole to study human economic activities, and we must treat economic activities as a subsystem of culture. Therefore, we cannot separate human economic activities from the existence of culture, which means that economic activities are not independent (Yang 1995:100-101).

In the development of the localization of economic anthropology, incorporating the theories of western economic anthropology and developmental economics by Chinese scholars has become very important. For example, Chen Qingde has made a profound reformulation of the concept of modernization from the Chinese anthropological perspective and this has become a significant paradigm in Chinese academic circles (Chen 2000). Yang Tingshuo analyzed and incorporated the development economics represented by Arthur Lewis, Theodore Schultz, and Myrdal Gunnar. His analysis and reflection featured a more critical approach using Chinese characteristics to develop economic anthropological theories in terms of critical acceptance and critical thinking.

Yang points out that although Lewis's development theory has a set of guidelines relevant to some aspects of economic development, and has established mileposts of great reference value, the theory has nevertheless oversimplified the complicated issues of economic development. Taking labor supply as an example, Lewis simplifies it into a headcount issue and fails to include issues such as quality of workers, labor ideology, and labor relationships. His model ignores the fact that it is impossible for the traditional agricultural industry to supply unlimited labor without destroying its existing production patterns, which in fact is a serious issue in terms of development. Moreover, Lewis's theory of wealth accumulation and capitalization has certain shortcomings because it has failed to explain the phenomenon that the Miao people will use for all their hard-earned money for daughters' jewelry. Furthermore, Lewis believes that the only way to realize modernization for a developing country is to follow western footsteps, which exhibits a lack of dialectical value; pays no attention to the different understandings of modernization by different ethnic groups; and therefore does not accurately portray reality (Yang 1995:141-6). 


\section{THEORETICAL MODEL WITH RICH CHINESE CHARACTERISTICS}

Professor Yang Tingshuo initially proposed his interphase-operating model in 1996. In Yang's work the concept of phase, as a complex term, is full of multiple social economic meanings. According to the current author's understanding, Yang utilizes different phases to refer to natural, economic, social and cultural environments in which different people from different nations manage their economic operations with their own unique model, scope, and characteristics. Every nation's economic operation model bears certain limitations in scale and administrative scope, including but not limited to natural, historical, political, and cultural factors (Yang 1995:39-52). The inter phase economic model is formed in the context of specific Chinese national conditions and backgrounds in a special period. Therefore, it has come very naturally with deeply branded distinct Chinese characteristics.

The interphase model theory is formatted significantly with the Chinese characteristics of various periods. Yang collected his data, penned it down and published his work during the middle but significant period when China was conducting its economic system reform. It has been over 35 years since the Chinese Communist Party's second-generation core leadership under Deng Xiaoping and his colleagues initiated the campaign for reform and opening. From a historical perspective, the reform and opening in China was necessarily inevitable. This great campaign brought the Chinese nation to a new era in the history of mankind enabling China play an increasingly key role in international affairs as a socialist country. Meanwhile, it has also promoted world peace and development at a very great degree. Therefore, China's reform and opening up has actually surpassed China's own needs as an independent nation and has become a part of the indispensable historical process of world economic and social development. On the other hand, the reform and opening campaign has made the Chinese economy rely on international capital, technology, and market with an increasing tendency becoming more obvious day by day. This process has increased opportunity cost for the process of China's reform and opening up.

It is true that China's reform and opening has displayed world-acclaimed achievements. However, we must point out that this campaign is a social revolution without a confirmed reference. It has suffered from lack of mature and authoritative theoretical guidance. Although the Chinese people have honored Deng Xiaoping as the general designer of the reform and opening up offering a bright road for the country, it is clear that the idealistic design of the reform and the actual situation often differ. In fact, during the actual process of the reform and opening, problems have inevitably occurred. For example, the issues of unbalanced regional development have become a very serious problem. Especially, the economic and social development in western minority areas is far behind the eastern regions. Facing the imbalance of regional development, the politicians and the economists of the country once launched a large-scale study, but, its effect is far from an ideal level (Li 2004). It requires new theoretical models to explore new ideas for an attempt to break through the seriously unbalanced deadlock in China's economic and social development for implementing further economic system reform, and enhancing economic and social development especially in minority areas. Yang's interphase operating model formulated in the context of such a rich background thus has a strong sense of the times and situation in China.

The interphase-operating model truly reflects the existence of Chinese national conditions and the reality of Chinese society. To study macroeconomic problems of China, it is necessary to start from basic Chinese national conditions. Similarly, to develop economic anthropology in China and to make it a theoretical guide for Chinese economic and social development, it is natural to start with a research on basic national conditions in China. Undeniably, a study of basic national conditions needs multi-disciplinary joint research. At the same time, researchers must be strategic, forward-looking, and innovative with courage and wisdom, and then they must make proposals for long-term development based on an in-depth analysis of the Chinese national situation. To understand and describe the national current situation, the focus of research points will naturally differ for different disciplines. In terms of economic anthropology, Yang's work is definitely a useful masterpiece which has come from his long-term research thoughts and crystallization of his wisdom on the strategy for the development of Chinese economic society in minority areas. 
Twenty years have passed from its initial publication. Today, after the current author read Yang's masterpiece, he cannot help but to deeply show his high respect and admiration for Yang and for his encouraging search of the facts; his farsightedness; and his sense of responsibility to the country of China and its people. Yang explicitly pointed out in the beginning that China's vast demobilization natural environment in various regions was not the same, and therefore economic development in different regions will have different models. At the same time, China is a country with many different ethnic groups whose cultural traditions vary greatly. Thus, when making social and economic development strategy in ethnic minority areas, it is necessary to consider ethnic factors along with other non-economic factors. Taking Guizhou Province as an example, Yang has analyzed the current economic and social development situation faced by ethnic groups in the western Chinese minority region. He has provided us with a true portrayal of the history and current economic and social development situation in the western Chinese minority areas (Yang 1995: 1-13)

Without a profound understanding of the basic Chinese situation, and without serious study and thinking about western Chinese ethnic minority regions, no scholar can reach the height of the knowledge and understanding that Yang has attained in terms of understanding the economy and society in western Chinese ethnic areas, let alone making detailed descriptions and meticulous analyses. Yang has adopted a method with Chinese characteristics in data collection, data processing and analysis, as well as deduction of conclusions. For example, in data collection, unlike substantialists who concentrate on the investigation of the community itself alone, Yang not only investigated natural and cultural characteristics of the community, but also noted China's national policy impact on the community, which paid more attention to the impact and influence that market-oriented economic reform and opening up generated for the community. Yang was seriously concerned with the collection of relevant information that reflected the influence of national development policies on the local community, as well as how the local people used their economic efforts to cater for the national trend.

With regard to data processing, while Yang used many statistics by the state, he also seriously considered that many non-market economic activities happened in the minority areas on daily basis. $\mathrm{He}$ sharply indicated that these activities were very difficult to be captured by the national statistical data. Therefore, in order to make conclusions, researchers must conduct participant observation and field studies by case analysis, and then compare and combine the case analysis conclusions and the statistics (Yang 1995:37-8). Clearly, all these facts and statements are especially applicable in the localization of economic anthropology with Chinese characteristics.

\section{ANTHROPOLOGICAL CASES WITH CHINESE CHARACTERISTICS}

One of economic anthropology's traditions is to make conclusions and theories through detailed analysis of specific cases (Chen 2010). The case study method, which is based upon the combination of economic and social reality, takes a typical case as the subject, and through specific analytical operations, demonstrates one or more theoretical issues, and then proposes corresponding solutions to solve social and economic problems of the people under the study. From this point of view, all successful ethnographic research projects of economic anthropology are exemplary case studies. The method of economic anthropologists differs from that of economists; the former relies on case studies and analyses to conduct studies, and the latter conducts studies mostly through mathematical models and statistical analysis. Therefore, to economic anthropologists, the more detailed and in-depth the case research materials are in hand, the more opportunities are there to discover the problems and put forward countermeasures. Yang's work contains more than one hundred detailed cases' analyses. This is one of the main reasons that his work has become a Chinese economic anthropology research paradigm.

Every case recorded by Yang is a true reflection of real life with significantly rich Chinese characteristics. For example, in Yang's book there is a description and analysis on the LiboYaoshan Bunu branch of the ethnic Yao people, who, when engaged in agricultural production activities, even in the busy harvest season, would not hesitate to cease their farming operations and begin hunting in the mountains once they found the trail of wild game. They confidently defended their behavior with the 
rationale that the crops in the field would not run away, but the beasts would disappear if they missed the opportunity to hunt. In Yang's analysis, it is not difficult to see that hunting is not a game or entertainment, but a legitimate economic behavior of the people. The previous non-anthropology researchers took this phenomenon as an example to show their disapproval of the Yao ethnic group. In their view, the Yao people, with backward ideas, did not care about the importance of agricultural production, which was the reason they had been suffering from long-term backwardness and poverty. Yang analyzes that the researchers' conclusion was erroneous because of not realizing the great differences in economic life styles and values between the Han majority people and the Bunu minority ethnic group. Moreover, the researchers only admit that agricultural production is the sole legitimate economic activity, while denying that hunting is an economic way of life. In the end, this is a typical bias derived from the stereotypes produced by the Han people's value system (Yang 1995:114-5). This case tells us that we must not violate the social existence and consciousness of culture held by our subjects in the research process of economic anthropology, otherwise, we may draw an ideal picture not in accord with reality, which could damage the subjects' normal way of life.

Yang argues that all economic activities are connected with investment, technology, personnel, and marketing. The customs of each nation have a non-negligible effect on these aspects. The interphase-operating mode requires that the operations of economic activities involve different ethnic groups to coordinate with their traditional customs and habits. But, there are always uncoordinated factors. Taking Huajiang Town of Guanling County in Guizhou as an illustration, the wine culture is unique and liquor consumption is huge in that town. Before reform and opening up, the distilleries provided major fiscal revenue for the county government. After the reform and opening up, the leadership decided to invest 10 million yuan to build a modern winery without a detailed feasibility study. The liquor produced by the modern winery is unmarketable, leading to a failure of marketing. The government had to shut down the modern distillery, and as a result, a 10-million-yuan investment became a pile of rotten iron. It is worth noting that annual fiscal revenue of the county was less than 8 million yuan at that time.

After closure of the new modern wine factory, workers went home to reopen their own small indigenous distilleries. They got the products sold on-site and the wine business became booming again. Yang indicates that in this case there is a common thread in the train of thought by those responsible for the economic development in minority regions in China: the only way to get rid of backward situations in minority areas is for them to introduce the most advanced technology and the most modern equipment.

According to this line of thinking, the newly built factories seemed very innovative and modern in ethnic minority regions, which helped inflate the local leaders' pretentiousness. The local leaders usually did not take the advice of ethnic minority people, and when this happens, the results will be either that the products are not marketable, or that the business operation model is not suitable to the local community, and failure is certain (Yang 1995:162-3). Such typical cases are likely to occur in China because of the tradition of a planned economy. Yang's book is full of this kind of vivid cases with Chinese characteristics. Each is a true portrayal of the phenomenon of a local economy and society. Today, when we read and think about these cases after 20 years since when Yang first published his book, we can still feel that it makes strong sense in current economic problems faced by the minority Chinese people. The cases serve as valuable data and materials for the construction and development of economic anthropology with Chinese characteristics.

\section{POLICIES PROPOSALS WITH CHINESE CHARACTERISTICS}

As highly applied behavioral science and social science, the study objects of economic anthropology include all human economic behaviors and economic system along with the economic models. In economic anthropology theory, research on development is an important topic, and can promote the growth and maturity of development economics to a great degree (Dai, Yin, and Dai 2012). In China, economic anthropology bears a great historical mission to investigate the full range of economic and social development in minority areas. Based on the investigation, economic anthropologists can put forward their policy suggestions and specific strategies to accelerate the economic and social 
development in ethnic minority areas. By doing so, it will enhance the development of economic anthropology with Chinese characteristics (Zhou and Liu 2003). China's economic and social development reality, especially the economic and social development reality in the minority regions of West China, requires special theoretical research and guidance from different disciplines, including economic anthropology. At the same time, it requires scholars to put forward concrete policy recommendations and implementation plans (Liu 2010). Therefore, in the process of learning and accepting western economic anthropology theory and methods, Chinese scholars should continuously innovate and develop economic anthropology theories and methods with Chinese characteristics. Thus, it shall become a glorious and historic mission for Chinese economic anthropology scholars to make better, newer, and greater contributions to build a comparatively well off society.

Chinese economic anthropologists never forget their holy mission. They go to small villages and high mountains to conduct numerous ethnographies of economic anthropology to put forward many insightful practical policy recommendations and specific implementation plans, and in order to provide strong evidence to support decision-making at both national and local levels for enhancing social and economic development in ethnic minority areas (Hu 2006). Yang's interphase operating theoretical model is one of many valuable policies oriented economic anthropology paradigms. In Yang's book, it is not difficult to find countermeasures and suggestions for social and economic development in ethnic areas of western China, especially the minority areas in Guizhou Province. All his proposals and suggestions are comprehensive with very original and visionary points. After nearly 20 years his theoretical model initially came into being, we can still feel a keen sense of its relevancy and practical significance when we read it even today.

Yang put forward his policy proposals and implementation strategies based on his profound economic anthropology investigations about various ethnic groups in Guizhou provinces. Yang's policy proposals and implementation suggestions differ from general policy measures offered by the government. Yang's policies operate under the guidance of economic anthropology theories. Therefore, they have a higher level of significance. For example, according to the contemporary Chinese social and economic condition, Yang has profoundly understood the minority regional strategy question: when making decisions, should the government focus on the Han Chinese developed areas or should they make the policies from the perspective of minorities? Next, Should the local leadership rely on material, labor, and technology, or should they rely on a better development policy? Finally, should the government make the development in ethnic minority areas on its own behalf or should the government mobilize the minority people to employ their own power?

Illustrated by many ethnographic cases in economic anthropology, Yang argues that the economy in minority regions in China, under the condition of a market economy, can develop to a great deal but its path must comply with the realities of minority regions, and must conform to the value system of minority culture. Otherwise, the economy cannot achieve the expected results and may cause negative outcomes regardless of how well the countermeasures or strategies are resorted to (Feng 1995). This point of view undoubtedly has its theoretical guiding significance for social and economic development in the ethnic minority areas, if the overall economic and social development level in the minority region is far lower than the national average level. Moreover, this point of view has very distinct Chinese characteristics; it is close to the local situation; it is close to the minority regional situation; and is close to the minority people. Therefore, it will have a long-term profound influence.

China is a developing socialist country. Both Chinese and foreign scholars have discussed socialist development issues for more than one hundred years from different angles (Ma 2010). Unlike other socialist countries, China has reformed its original socialist planned economic system into a more market-oriented economy in last 36 years. It has creatively opened up a socialist market economic development path with Chinese characteristics. In the transition from a planned economy to a market economy, these two kinds of economic development policies profoundly influenced the social economic development of the ethnic minority regions. Yang has his own sharp understanding on this. He clearly points out that current economic development in ethnic minority areas has lagged not because of the implementation of the planned economic policy of the government, but, because the program is out of 
control. Yang does not believe that there should be an absolute opposition of socialist planning and free market ideas.

Because of the complexity of ethnic regional conditions, and as reform of the economic system in the ethnic minority areas has not been as penetrating as that in the eastern developed area, it is difficult to completely get rid of the current planned economic system. In other words, ethnic minority areas still need national government support in some respects for their development. Therefore, in the formulation of social and economic development policies, decision makers must consider the reality of ethnic minority areas. In other words, the development policy should be diversified, targeted and full of flexibility (Yang 1995:409). From this perspective, Yang has put forward a specific series of policy suggestions and measures for social and economic development in minority areas of Guizhou province, which are still effective today.

\section{CONCLUSION}

Professor Yang Tingshuo's book Principles in Xiangji Operation is based on numerous ethnographic economic anthropology findings. The book probes social and economic development issues in ethnic minority regions in China. By digesting and integrating the foremost theoretical models of domestic and foreign economic anthropology, cultural anthropology as well as economics, Yang's book proposes a new economic anthropology paradigm with Chinese characteristics. It applies extensive and detailed research to delve into the contemporary world's economic systems which are beset with problems of poverty, inequality, and underdevelopment. From this point of view, now that Yang's book has been officially published for nearly 20 years, we still believe that the Xiangji (interphase) economic operational principles have their theoretical significance for China's comprehensive construction of a prosperous society. Yang's frameworks not only provide theoretical guidance and a practical scheme for a new round of economic construction in Guizhou, but, they will do the same for western regions in China, and even for the areas in the rest of the world which face similar regional, social and economic conditions in terms of social and economic development in the world. As such, we are confident that Yang's theoretical model provides us an economic anthropology paradigm for modern China.

The interphase operating model passes beyond traditional economic assumption, including the assumption of the rational person and the assumption that abstract thinking governs human economic activities. Yang's model also transcends the traditional anthropology paradigm which advocates a comparative study of human economic activities from the aspect of decision theory, motivational analysis, and cultural impact. The model enriches economic anthropology theories, and at the same time, it pushes development studies towards a new climax. The new theory of interphase operating model is full of Chinese characteristics, and helps the localization of economic development in China. In short, the model not only has opened up a new path of economic anthropology localization in China, but it has also offered a new paradigm for economic and social development in the ethnic areas of western China, and also in similar regional areas. It certainly has provided a valuable guide for the theoretical model of economic anthropology in general.

\section{ACKNOWLEDGEMENT}

Dr. Jiang Youchun is the corresponding author. This study is supported by the National Philosophy and Social Sciences Fund Project of P. R. China entitled: A Study of the Cultural Inheritance and Creativity in the Reaches of Yuan River(18BMZ066). 


\section{REFERENCES}

Carrier, J. G. (2005). A Handbook of Economic Anthropology. Northampton, MA: Edward Elgar. Chen, Q. (2000). Reflection on Modernization in the View of Economic Anthropology. Strategy and Management, (1), 72-85.

Chen, Q. (2010). Application and transformation of formal analysis in economic anthropology.Journal of Guangxi University for Nationalities, (4), 47-54.

Dai, M., Yin, Y., \& Dai, X. (2012). Innovation Theory 1912-2012: Commemorate the Theory of Economic Development First Edition of 100 Anniversary. Economics Trends, (4), 143-150.

Dalton, G. (1971). Traditional Tribal and Peasant Economics: An Introductory Survey of Economic Anthropology. Addison: Wesley Publishing Company, Inc.

Fan, X. (2009). The Economic Anthropology Research in China. Journal of Huaihua University, 28(12), 21-24.

Fang, M., Wang, C., Hong, W. A., \& Tian, G. (2019). Development of Business Anthropology in China. Human Organization, 78(2), 158-168.

Feng, Z. (1995). Preface. In Yang Tingshuo, Interphase Operational Principles. Guiyang, Guizhou: Guizhou People Publishing House 1-5.

Gudeman, S. (2001). The Anthropology of Economy. Malden, MA: Blackwell.

Halperin, R. H. (1988). Economies across Cultures: Towards a Comparative Science of the Economy. New York: St. Martin's Press.

Hann, C., \& Hart, K. (2011). Economic Anthropology. Cambridge, UK:Polity Press.

Hornborg, A. (2005).Resisting the black hole of neo-classical formalism in economic anthropology. In Peopled Economies: Conversations with Stephen Gudeman, edited by S. Löfving,63-80. Uppsala: Interface.

Hu, H. (2006). History of Chinese Anthropology. Beijing: Renmin University of China Press.

Li, Z. (2003). Ethnic People's Economic Interest Is Relative Independence. Journal of Gansu College of Political Science and Law for Adult Education, (3), 123-125.

Li, Z. (2004). New Development of Ethnic Economics. Beijing: National Publishing House.

Liu, H. (2010). The Chinese Economists' Glory and Dream in 1980s. Nanning, Guangxi: Guangxi Normal University Press.

Ma, Y. (2010). System and the Path: The History and Reality of Socialist Economic Reform. Beijing: People's Publishing House.

Mayhew, A. (1980). Atomistic and Cultural Analyses in Economic Anthropology: An Old Argument Repeated. In Institutional Economics: Contributions to the Development of Holistic Economics Essays in Honor of ALLAN G. GRUCHY, edited by John Adams, 72-81. Boston: Martinus Nijhoff Publishing.

Nash, J. (1981). Ethnographic Aspects of the Word Capitalist System. Annual Review of Anthropology, $10,393-423$.

Ortiz, S. (1983). Economic Anthropology:Topics and Theories. Lanham, MD:University Press of America and Society for Economic Anthropology.

Shi, L. (2002). Economic Anthropology. Beijing: Central Minzu University Press.

Shi, Z. (1993). An Introduction to Ethnic Economics. Beijing: Minzu Publishing House.

Tian, G. (2014). Economic Anthropology with Chinese Characteristics. Yang Tingshuo Xiangji Operational Theoretical Model. Anthropologist, 17(2), 311-318.

Tian, G. (2013). Paradigm of Economic Anthropology in China: Academic Thought of Yang Tingshuo's Interphase Operational Model. Journal of China Minzu University, 2013(5), 11-16.

Tian, G., \& Han, G., et al. (1987). Choice and Development: Economic Revitalization of the Western Ethnic Regions in China. Beijing: Current Affairs Press.

Tian, G., \& Luo, K. (2013). Economic Anthropology. Yinchuan, Ningxia: Ningxia People's Publishing House. 
Yang, T. (1995). Interphase Operational Principles. Guiyang, Guizhou: Guizhou People Publishing House.

Zhou, D. (2013). Preface. In Tian, Guang and Luo, Kanglong, Economic Anthropology, 1-3 Yinchuan: Ningxia People's Publishing house.

Zhou, D., \& Liu, Z. (2003). Chinese anthropology review. In 21 Century Anthropology, edited by Zhou Daming, 1-13. Beijing: National Publishing House. 